\title{
COMO SERÁ O AMANHÃ? O MUNDO PÓS-PANDEMIA
}

Mariana Guenther ${ }^{1}$

Resumo: A pandemia da COVID-19 nos forçou a repensar muitos de nossos hábitos e costumes, nos fez reinventar formas de nos relacionar com o mundo e nos trouxe importantes reflexões sobre o que realmente importa para nossas vidas e sobre os resultados das nossas atitudes em relação ao meio ambiente. Nesse artigo discuto como os impactos ambientais estão relacionados ao surgimento de doenças, analiso os efeitos do isolamento social sobre o meio ambiente, e proponho algumas mudanças que podemos pôr em prática no futuro, diante de todas as reflexões impostas por esse momento que estamos vivendo. A educação ambiental tem um papel fundamental nesse processo de reflexão e ação, e será nossa grande aliada nessa próxima década.

Palavras-chave: COVID-19; Meio Ambiente; Educação; Ciência; Impactos.

Abstract: The COVID-19 pandemic forced us to rethink many of our habits and behaviors, made us reinvent ways of connecting to the world, and brought us important reflections on what really matters to our lives and the results of our actions towards the environment. In this article I discuss how environmental impacts are related to the emergence of diseases, analyze the effects of social isolation on the environment, and propose some changes that we can put into practice in the future, given all the reflections imposed by this moment. Environmental education has a fundamental role in this process of think and act, and will be our greatest ally during the next decade.

Keywords: COVID-19; Environment; Education; Science; Impacts.

1Universidade de Pernambuco. E-mail: mariana.guenther@upe.br 


\section{Introdução}

Tudo começou no fim de dezembro de 2019, no município de Wuhan (Hubei, China), quando o primeiro caso de COVID-19 ("Coronavirus Disease19") ou 2019-nCoV ("Doença do novo coronavírus 19) foi comunicado pela Comissão de Saúde do Município de Wuhan à Organização Mundial da Saúde - OMS (WHO, 2020a). O vírus causador dessa doença, SARS-CoV-2 ou novo coronavírus, rapidamente se espalhou pelo mundo, levando a OMS a declarar Emergência de Saúde Pública de Importância Internacional (ESPII) em 30 de janeiro de 2020, com casos registrados em 19 países (WHO, 2020b).

Desde então os números de casos e óbitos cresceram exponencialmente e muito rapidamente no mundo inteiro (WHO, 2020c). No Brasil, a Emergência em Saúde Pública de Importância Nacional (ESPIN) em decorrência da infecção humana pelo novo coronavírus foi declarada em fevereiro de 2020, através da Portaria no 188/20 (BRASIL, 2020).

Essa situação nova e inesperada transformou o mundo em poucos dias. Novas formas de comunicação, novas estratégias de trabalho, novas reflexões sobre nossas relações com o mundo foram se apresentando ao longo desses meses de isolamento social.

E toda essa tragédia que estamos vivendo atualmente devido a pandemia da COVID-19 é reflexo direto de nossas relações com o meio ambiente. Essa doença nos mostra que toda ação resulta em uma reação, e a grande questão agora é definir que atitudes tomaremos diante de tudo o que está acontecendo. Finalmente modificaremos nossos hábitos e costumes ou simplesmente assistiremos ao fim da humanidade?

Nesse artigo discuto como nossos impactos sobre o ambiente estão diretamente relacionados ao surgimento de doenças, analiso os efeitos do isolamento social sobre o meio ambiente e proponho algumas mudanças que podemos pôr em prática no futuro, diante de todas as reflexões impostas por esse momento que estamos vivendo.

\section{Impactos ambientais e o surgimento das doenças}

Desde a identificação do novo coronavírus na China (ZHU et al., 2020), vários estudos genéticos foram desenvolvidos para se entender a origem desse vírus (LU et al., 2020). A família Coronaviridae é bastante extensa, com 5 gêneros e pelo menos 46 espécies conhecidas (WOO et al., 2010; ICTV, 2019). Muitas delas vivem em animais silvestres, algumas em animais domésticos e algumas em humanos. Os coronavírus que infectam cães por exemplo são diferentes daqueles que infectam gatos que por sua vez não são os mesmos que infectam animais silvestres ou humanos (HAMRE; PROCKNOW, 1966; FEHR; PERLMAN, 2015; LIM et al., 2016).

O que sabemos até o momento é que há uma grande semelhança genética entre o SARS-CoV-2 e outros coronavírus naturalmente existentes em morcegos (BANERJEE et al., 2019; LU et al., 2020). Essa semelhança com 
coronavírus de morcegos também já havia sido identificada em outros coronavírus que já causaram epidemias humanas no passado como o SARSCoV (LI et al., 2005; LAU et al., 2005) e o MERS-CoV (MEMISH et al., 2013; CHASTEL, 2014).

O SARS-CoV, coronavírus bem semelhante ao atual, foi o causador da SARS (ou SRAG) - Síndrome Respiratória Aguda Grave, que surgiu em 2002 em Guangdong na China, afetando 8098 pessoas no mundo inteiro e causando a morte de 774 pessoas (CDC, 2017). O MERS-CoV é o causador da MERS (ou SROM) - Síndrome Respiratória do Oriente Médio, que surgiu em 2012 na Arábia Saudita e em outros países do Oriente Médio atingindo 2260 pessoas em 27 países e causando 803 mortes (VAN BOHEEMEN et al., 2012; WHO, 2020d).

Desde o início da pandemia da COVID19, os morcegos passaram a ser vistos como os grandes vilões causadores de todo esse mal que nos assola. $E$ muitos passaram a perseguir esses animais como se isso fosse resolver o problema da doença. Os morcegos apresentam uma grande resistência a doenças virais, sendo aparentemente imunes a uma grande variedade de vírus que são patogênicos a outros vertebrados, inclusive ao homem, e por isso são apontados como importantes reservatórios de vírus (CALISHER et al., 2006; MORATELLI; CALISHER, 2015). De fato, mais de 200 vírus pertencentes a 27 famílias já foram detectados em morcegos, sendo que alguns deles também infectam humanos, como o vírus Marbug, o vírus Ebola, e o vírus da febre amarela, além dos coronavírus mencionados anteriormente (CALISHER, 2015).

Estudos que investigam a origem do SARS-CoV-2, bem como de outros coronavírus que causaram epidemias humanas no passado, mostram que outros animais silvestres podem ter atuado como hospedeiros intermediários dos vírus, como as civetas para o SARS-CoV, os camelos para o MERS-CoV e o pangolim para o SARS-CoV-2. Em todos esses animais foram encontrados coronavírus semelhantes aos causadores dessas doenças no homem (GUAN et al., 2003; AZHAR et al., 2014; MEMISH et al., 2014; MEYER et al., 2014; XIAO et al., 2020; LAM et al., 2020).

Outros animais, além dos morcegos, também são infectados por vírus que atingem o homem, como o HIV e o vírus da febre amarela, encontrados nos primatas (GARDNER; RYMAN, 2010; SHARP; HAHN, 2011), ou o vírus H5N1, causador da gripe aviária, encontrado em aves silvestres e domésticas, e o vírus $\mathrm{H} 1 \mathrm{~N} 1$, causador da gripe suína e da gripe espanhola, encontrado em aves e suínos (SIMS et al., 2005; SMITH et al., 2009; ANHLAN et al., 2011).

Analisando então todas essas doenças virais que acometem os humanos chegamos a um denominador comum: todos esses vírus são encontrados em animais silvestres. Ao que então perguntamos: como esses vírus têm chegado até nós? Por que tais doenças têm emergido com mais frequência ultimamente? 
A resposta é assustadoramente simples: os vírus não têm chegado a nós, mas sim nós chegamos a eles. Os ambientes naturais abrigam uma grande diversidade de espécies que interagem harmonicamente entre si. Plantas, animais, fungos, bactéria e vírus coexistem em uma rede complexa de interações. No entanto, quando o ambiente é perturbado, essas interações são desfeitas, e as espécies modificam seus hábitos em resposta a essa perturbação como forma de adaptação à nova realidade.

A ocupação humana dos ambientes naturais afeta diretamente as relações harmônicas entre as espécies. As mudanças climáticas causadas pela nossa utilização exacerbada dos combustíveis fósseis, a poluição do ar, das águas e do solo, o desmatamento e a caça predatória alteram drasticamente o modo de vida de todas as espécies. Quando invadimos uma área florestada para construirmos nossas casas, por exemplo, estamos alterando permanentemente o habitat de uma grande variedade de animais silvestres e, consequentemente, aumentando nosso contato com eles e seus vírus. Mas nós, ao contrário das espécies que convivem com os vírus ao longo de milhares de anos, não temos defesas naturais, e assim surgem as epidemias.

Ao observarmos nossa fauna urbana, repleta de ratos, pombos, gambás, morcegos, esquilos, macacos, guaxinins, percebemos que não foram os animais silvestres que chegaram às cidades, e sim as cidades invadiram seus habitats e eles tiveram que se adaptar. Nossas cidades acumulam uma grande quantidade de alimento para esses animais - nosso "lixo", e como eles não encontram tantos predadores naturais, se reproduzem em maior quantidade e por isso são tidos como pragas. Essa mudança na estrutura das comunidades animais facilita a transmissão de patógenos entre eles e deles para nós.

A vida na cidade também contribui para a transmissão de doenças entre humanos, como temos observado atualmente com a COVID-19. O ar poluído, os transportes públicos lotados, as condições precárias de higiene, a má alimentação e o estresse do dia-a-dia, são fatores que aceleram o desenvolvimento dessas epidemias.

\section{A poluição durante a quarentena}

$\mathrm{O}$ isolamento humano resultou em mudanças ambientais inesperadas. A redução da circulação de veículos e do funcionamento das indústrias devido a pandemia resultou em uma forte queda nos níveis de gases tóxicos na atmosfera.

Imagens de satélite divulgadas pela NASA, a Agência Espacial dos EUA, mostraram uma drástica redução nas concentrações de dióxido de nitrogênio atmosféricos $\left(\mathrm{NO}_{2}\right)$ na China no período em que foi decretada a quarentena (Figura 1). $\mathrm{O} \mathrm{NO}_{2}$ é um gás emitido essencialmente por veículos, através da queima dos combustíveis fósseis, e pelas indústrias. É um gás extremamente nocivo à saúde, causando vários problemas respiratórios, além de ser um dos gases responsáveis pela chuva ácida e pelo efeito estufa (WHO, 2000e). 


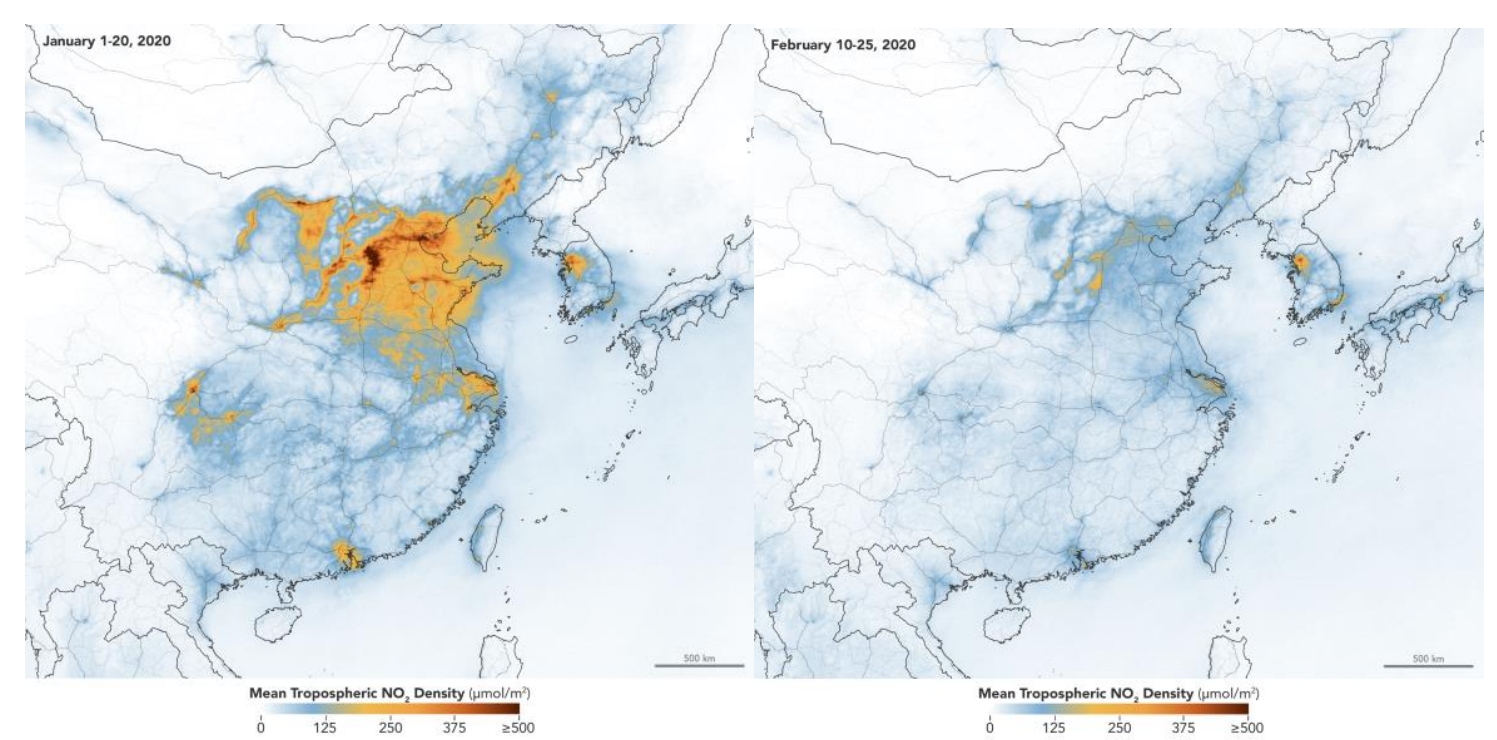

Figura 1: Concentração de $\mathrm{NO}_{2}$ atmosférico no norte da China em janeiro de 2020 (esquerda) e em fevereiro de 2020, após o decreto de isolamento domiciliar (direita).

Fonte: NASA (2020)

A poluição atmosférica é um problema crônico na China, em função da intensa produção industrial e grande circulação de veículos, o que resulta em altos índices de doenças respiratórias, hipertensão e diabetes (TIE-GANG et al., 2018; BOWE et al., 2018). Durante a pandemia da SARS em 2002-2003, estudos mostraram que as taxas de mortalidade por SARS foram maiores nas cidades chinesas mais poluídas como Beijing e Tianjin, localizadas na região norte do país (CUI et al., 2003). A redução da poluição na China durante a atual quarentena foi de tal magnitude que estimativas mostraram que a quantidade de óbitos por COVID19 pode ter sido menor do que os potenciais óbitos resultantes da poluição, quando comparada às taxas de mortalidade nos anos passados no mesmo espaço de tempo (BURKE, 2020)

Mas não foi só a China que experimentou essa redução da poluição atmosférica. Outras grandes cidades como Nova Delhi, Los Angeles, Bangkok, Bogotá, Paris e São Paulo também registraram quedas significativas nos níveis de gases poluentes durante o período de isolamento. Essa mudança foi percebida por todos: dias ensolarados com céus azuis, cenários raros na maior parte das grandes cidades ao redor do mundo, foram comemorados e desfrutados durante a quarentena (ELLIS-PETERSEN et al., 2020; NEWBURGER; JEFFERY, 2020; REGAN, 2020).

A poluição sonora também diminuiu drasticamente com a redução da circulação de pessoas e automóveis nas ruas. Pássaros passaram a ser vistos nas varandas dos apartamentos, nas árvores das praças, nas praias e parques. Vários outros animais foram flagrados circulando pelas ruas vazias das cidades, passeando tranquilamente sem a influência dos humanos (NEWBURGER; JEFFERY, 2020). Tais imagens inundaram as redes sociais 
seguidas de mensagens de alegria e esperança, mostrando os efeitos da ausência do homem sobre a natureza.

Muitas dessas imagens eram falsas, de fato. Seja por não retratarem o local a que se referiam, sejam por terem sido feitas em outro momento, fora do contexto da pandemia, seja por simplesmente tratar de animais comumente encontrados nesses locais (DALY, 2020). Mas a "viralização" dessas imagens, falsas ou não, reflete o desejo das pessoas em voltar a ter um ambiente livre de poluição. De fato, mesmo desmentidas, muitas dessas falsas imagens continuaram sendo replicadas, e muitas pessoas criticaram aqueles que desmentiam tais "fake news", alegando que, mesmo falsas, essas notícias trazem alento e esperança nesses momentos tão difíceis (BALE, 2020).

Mas nem todas as notícias em relação à poluição durante a quarentena são boas. Apesar da redução da poluição atmosférica e sonora em função da diminuição da circulação de veículos e pessoas, o acúmulo de resíduos sólidos não diminuiu. Além disso, o uso de materiais descartáveis como luvas, máscaras, protetores faciais, aventais e macacões pelos profissionais de saúde, aumentou enormemente nesse período.

O novo coronavírus é classificado como agente biológico de classe de risco 3 - transmissão de alto risco individual e moderado risco para a comunidade, segundo a Classificação de Risco dos Agentes Biológicos do Ministério da Saúde (BRASIL, 2017). Sendo assim, todos os resíduos provenientes de contato com possíveis infectados com o novo coronavírus devem ser enquadrados na categoria A1- agentes biológicos com alto risco de infecção, conforme Resolução RDC/Anvisa no 222 de 2018 (BRASIL, 2018). Tais resíduos devem ser separados e acondicionados em sacos resistentes e tratados para eliminação da carga viral para então serem descartados.

Nas unidades de saúde é possível realizar a separação, armazenamento e encaminhamento para tratamento desses resíduos. No entanto, o problema maior está nos materiais descartáveis utilizados pela população, como luvas e máscaras, que são descartados no lixo comum e misturados a outros resíduos. Além de aumentar a possibilidade de transmissão do vírus, esses resíduos vêm se acumulando e se somando ao grande problema já existente de gerenciamento dos resíduos sólidos em âmbito global (FLETCHER, 2020).

\section{Reflexões da quarentena: um mundo melhor é possível?}

Toda essa situação que estamos vivendo gera muitas reflexões. Repensamos nossas prioridades, nossos hábitos quanto a nossa saúde, tentamos nos alimentar melhor para combater a doença, procuramos meios de manter a mente e coração tranquilos, buscando uma luz no meio de tanta desesperança. Cuidamos também do ambiente a nossa volta, mesmo que o ambiente se resuma às quatro paredes que nos cerca nesse isolamento. Limpamos nossas casas repetidamente, seja por medo da contaminação, seja 
por excesso de tempo ocioso. Trazemos plantas para nossas varandas, abrimos janelas, tentamos olhar para fora contando os dias para estarmos novamente caminhando nas areais da praia, tomando um banho de rio, correndo no parque, ou levando as crianças para brincar na praça, contemplando a paisagem que agora se resume às fotos compartilhadas nas redes sociais.

O que deixamos de fazer durante essa quarentena e não precisamos voltar a fazer? O que passamos a fazer e deveríamos continuar ao fim desse período? Essa é uma reflexão primordial e urgente.

\section{Meios alternativos de transporte}

A redução da circulação de carros e das atividades industriais tiveram um grande efeito na redução das taxas de poluição atmosférica. E esse efeito foi sentido tanto em escala local quanto global. Alguns estudos estimam uma redução nas emissões globais de carbono durante o ano de 2020 como resultado do isolamento, dependendo do tempo em que durar a quarentena (LE QUÉRÉ et al., 2020). E isso é um dado inédito. Será que não seria o momento de deixarmos efetivamente de lado os automóveis tão poluentes e buscarmos alternativas de transporte?

Muitas distâncias são facilmente percorridas por bicicletas, por exemplo, o que traz um enorme benefício para nossa saúde e para o ambiente. Várias cidades do mundo já utilizam as bicicletas como o principal meio de transporte, no entanto é preciso um planejamento urbano para que isso aconteça. Ciclovias separadas das vias para automóveis e ônibus são fundamentais para que os ciclistas possam circular com segurança. A educação da população nesse sentido também contribui sobremaneira para o sucesso dessa forma mais saudável e menos poluente de se deslocar pelas cidades.

Transporte públicos menos poluentes como trens ou metrôs elétricos precisam se tornar alternativas viáveis financeiramente para as grandes cidades. É necessário um investimento nesses transportes em detrimento daqueles movidos à gasolina ou diesel. Muitas cidades brasileiras ainda possuem um sistema de transporte público muito precário, forçando as pessoas que possuem melhores condições financeiras a utilizarem seus próprios automóveis. Isso gera grandes congestionamentos e altas taxas de poluição sonora e atmosférica. Transportes públicos menos poluentes precisam ser prioritários no planejamento das grandes cidades.

\section{Trabalho remoto}

O isolamento social nos fez buscar alternativas para continuar trabalhando de forma remota. Sabemos que a inclusão digital de todos ainda é um sonho distante, mas precisa ser uma meta para os próximos anos. A 
pandemia nos mostrou que é possível trabalhar de casa. Muitos se sentem inclusive mais produtivos, pois economizam o tempo gasto de deslocamento de casa para o trabalho. Para a maioria dos trabalhadores, esse deslocamento pode representar de 25 a $40 \%$ do seu tempo de trabalho.

Além disso há a economia no custo do transporte ou no combustível, e nas refeições, que são mais custosas e menos saudáveis quando feitas fora de casa. Mesmo incluindo os custos da internet, o trabalho remoto compensa financeiramente. Sem contar o estresse do trânsito que tem um efeito profundo na nossa saúde. O trabalho remoto tem, portanto, uma implicação direta na saúde física e mental do indivíduo, no funcionamento das cidades e na preservação ambiental. Quanto menos gente nas ruas, menos trânsito, menos barulho, menos poluição. E essa seria uma solução possível para as grandes cidades.

\section{Inclusão digital}

Mas nem todos os tipos de trabalho são viáveis de forma remota. A desigualdade social em muitos países, e principalmente no Brasil, se mostra ainda mais evidente nesses tempos de pandemia. Nem todos podem praticar o isolamento e trabalhar de casa, muitos precisam sair todos os dias em transportes públicos lotados para garantir o sustento de suas famílias. Muitos não têm as condições de saneamento necessárias para garantir uma boa higienização, e muitos não tem acesso a tratamento médico adequado, visto que os sistemas de saúde não têm a capacidade de atender a todos.

E dentre as tantas faces da desigualdade social no Brasil, temos também a desigualdade digital. $O$ ensino remoto, por exemplo, tem se mostrado uma realidade inviável para grande parte dos estudantes brasileiros. A dificuldade de acesso à internet, ou a falta de equipamentos como computadores, tablets ou celulares para acompanhar as aulas remotas tornam esse formato de ensino totalmente utópico.

É preciso um investimento maciço em equipar e capacitar professores e estudantes das redes pública e privada de ensino para essa nova realidade que estamos vivendo. Os estudantes estão há mais de quatro meses sem aulas presenciais, tentando seguir aulas remotas de forma precária, sem a estrutura necessária, que também são oferecidas sem o devido planejamento por não ter havido treinamento adequado para os docentes. É claro que essa é uma situação emergencial e inesperada, mas podemos aprender com a crise e melhorar o sistema de ensino para o futuro. Mesmo no mundo pós pandemia, o ensino a distância já se mostra uma ferramenta complementar muito útil na educação, que deve ser implementada tanto no Ensino Médio quanto no Ensino Superior. 


\section{Consumo consciente}

O isolamento também nos fez rever algumas prioridades de consumo. Passeios no shopping eram programas de família nos fins de semana. Com um lanchinho aqui, um cineminha ali, algumas comprinhas no caminho, e lá se ia o salário do mês. Sobrevivemos durante meses sem ir ao shopping, cozinhando em casa, passando mais tempo em família, lendo mais livros, assistindo mais filmes, ouvindo mais músicas. E de repente passamos a perceber o que de fato gostamos e o que de fato fazíamos por simples hábito.

Nossa relação com os alimentos também mudou. As compras nos mercados passaram a ser desafiadoras, pois são focos de contaminação. É preciso ir direto ao ponto e comprar apenas o necessário. Não podemos desperdiçar alimentos, pois isso implicará em uma nova ida ao mercado e a gastos que nesse momento em que estamos todos sofrendo com as perdas de emprego ou redução de salário, são decisivos. Damos mais valor às refeições feitas em casa, cozinhamos mais, e aproveitamos melhor os alimentos.

Acredito, portanto, que nossos hábitos de consumo também poderão mudar no mundo pós pandemia. O consumo consciente e sustentável deverá ser incorporado pela sociedade. Pensaremos melhor antes de comprar e daremos mais valor ao nosso dinheiro. $E$ isso tem um impacto direto no ambiente: quanto menos consumimos, menos descartamos, menos resíduos geramos, e o planeta agradece.

\section{Confiança na ciência}

A pandemia da COVID-19 também nos fez refletir na importância da ciência. Ainda enfrentamos novos surtos de doenças que já haviam sido erradicadas como o sarampo, por exemplo, em função do crescimento do número de pessoas que não acreditam na eficácia das vacinas, ou que acreditam que elas tenham graves efeitos colaterais (MOSS, 2017; CDC, 2020). Mas percebemos que as pessoas estão hoje de olhos mais abertos e ouvidos mais atentos para qualquer achado científico sobre medicamentos que curem ou vacinas que previnam a COVID-19.

A confiança na ciência pela população de fato aumentou nesses tempos de pandemia. Uma pesquisa recente do IDEIA Big Data mostrou que, para $76 \%$ dos brasileiros, o interesse em ouvir cientistas e pesquisadores sobre a pandemia aumentou (IDEIA, 2020). Todos dependemos dos cientistas para sairmos dessa situação o mais rápido possível, e agora estamos mais conscientes disso. Milhares de artigos são publicados a cada semana e todo o mundo científico está focado em um só problema, em uma só finalidade: a cura da COVID-19.

Assim, também espero que no mundo pós pandemia, cientistas sejam mais respeitados e mais ouvidos, que a ciência receba mais investimentos públicos e privados, e que a profissão cientista seja mais almejada pelos nossos jovens.

revista brasileira educação ambiental 


\section{Conclusões}

A pandemia nos mostrou que não é possível continuarmos vivendo desta forma agressiva e irresponsável em relação ao meio ambiente. Novas epidemias como essa ou piores estão por vir se continuarmos derrubando nossas florestas, poluindo nossas águas, tornando nosso ar irrespirável. Se não agirmos rápido, extinguiremos nossa espécie em poucas gerações.

Mas acredito na possibilidade de mudanças reais. As crises nos fazem refletir e nos reinventar. Conhecemos os problemas e temos as soluções, só precisamos colocá-las em prática. Esse artigo buscou promover essa reflexão através de informações e evidências científicas. A educação ambiental tem um papel fundamental nesse processo de reflexão e ação, e será nossa grande aliada nessa próxima década.

\section{Referências}

ANHLAN, D et al. Origin of the 1918 pandemic H1N1 influenza A virus as studied by codon usage patterns and phylogenetic analysis. RNA, v. 17, n. 1, p. 64-73, 2011. DOI:10.1261/rna.2395211

AZHAR E. I. et al. Evidence for camel-to-human transmission of MERS coronavirus. The New England Journal of Medicine, v. 370, n. 26, p. 24992505, 2014. DOI: 10.1056/NEJMoa1401505

BALE, R. Why do people want so badly to believe this fake story is true? National Geographic, Washington D.C., 27 mar. 2020. Disponível em: $<$ https://www.nationalgeographic.com/animals/2020/03/why-do-people-want-sobadly-to-believe-this-fake-story-is-true/>. Acesso em 22 jun. 2020.

BANERJEE, A. et al. Bats and Coronaviruses. Viruses, v. 11, n. 41, online, 2019. DOI:10.3390/v11010041

BOWE, B. et al. The 2016 global and national burden of diabetes mellitus attributable to PM2.5 air pollution. Lancet Planetary Health, v. 2, n. 7, p. e301e312, 2018. DOI:10.1016/S2542-5196(18)30140-2

BRASIL. Portaria MS n. 2.349, de 14 de setembro de 2017. Aprova a Classificação de Risco dos Agentes Biológicos elaborada em 2017, pela Comissão de Biossegurança em Saúde (CBS), do Ministério da Saúde. Disponível em: http://bvsms.saude.gov.br/bvs/saudelegis/gm/2017/prt2349 2209 2017.html. Acesso em 22 jun. 2020.

BRASIL. Portaria MS/GM n. 188, de 03 de fevereiro de 2020. Declara Emergência em Saúde Pública de importância Nacional (ESPIN) em decorrência da Infecção Humana pelo novo Coronavírus (2019-nCoV). Brasília, DF, 2020. Disponível em: <http://www.in.gov.br/web/dou/-/portaria-n-188-de-3de-fevereiro-de-2020-241408388>. Acesso em 20 jun. 2020. 
BRASIL. Resolução MS/ANVISA RDC n. 222, de 28 de março de 2018. Regulamenta as Boas Práticas de Gerenciamento dos Resíduos de Serviços de Saúde e dá outras providências. Brasília, DF. Disponível em: $<$ http://portal.anvisa.gov.br/documents/10181/3427425/RDC 2222018 .pdf/>. Acesso em: 22 jun. 2020.

BURKE, M. COVID-19 reduces economic activity, which reduces pollution, which saves lives. Global Food, Environment and Economic Dynamics. online, 2020. Disponível em: <http://www.g-feed.com/2020/03/covid-19reduces-economic-activity.html>. Acesso em 21 jun. 2020.

CALISHER, C. H. et al. Bats: important reservoir hosts of emerging viruses. Clinical Microbiology Reviews, v. 19, n. 3, p. 531-545, 2006.

CALISHER, C. H. Viruses in bats: a historic review. In: WANG, L. F.; COWLED, C. (eds). Bats and viruses: from pathogen discovery to host genomics. New York: John Wiley \& Sons, p. 23-45, 2015.

CDC - Centers for Disease Control and Prevention. Global Measles Outbreaks. $\quad 2020.2$ Disponível em: $<$ https://www.cdc.gov/globalhealth/measles/globalmeaslesoutbreaks.htm>.

Acesso em 22 jun. 2020

CDC - Centers for Disease Control and Prevention. Severe Acute Respiratory Syndrome. Atlanta, 2017. Disponível em: <https://www.cdc.gov/sars/about/fssars.html>. Acesso em 21 jun. 2020.

CHASTEL C. Middle East respiratory syndrome (MERS): bats or dromedary, which of them is responsible? Bulletin de la Sociéte de Pathologie Exotique, v. 107 , n. 2, p. 69-73, 2014.

CUI, Y. et al. Air pollution and case fatality of SARS in the People's Republic of China: an ecologic study. Environmental Health, v. 2, n. 15, online, 2003.

DALY, N. Fake animal news abounds on social media as coronavirus upends life. National Geographic, Washington D.C., 20 mar. 2020. Disponível em: $<$ https://www.nationalgeographic.com/animals/2020/03/coronavirus-pandemicfake-animal-viral-social-media-posts/>. Acesso em 22 jun. 2020.

ELLIS-PETERSEN, H. et al. 'It's positively alpine!': Disbelief in big cities as air pollution falls. The Guardian, Londres, 11 abr. 2020. Disponível em: $<$ https://www.theguardian.com/environment/2020/apr/11/positively-alpinedisbelief-air-pollution-falls-lockdown-coronavirus>. Acesso em 22 jun. 2020.

FEHR A.R.; PERLMAN S. Coronaviruses: an overview of their replication and pathogenesis. In: MAIER H.; BICKERTON E.; BRITTON P. (eds) Coronaviruses. Methods in Molecular Biology, vol 1282. New York: Humana Press, p. 1-23, 2015. 
FLETCHER, C. What happens to waste PPE during the coronavirus pandemic? The Conversation, Boston, 12 mai. 2020. Disponível em: $<$ https://theconversation.com/what-happens-to-waste-ppe-during-thecoronavirus-pandemic-137632>. Acesso em 22 jun. 2020.

GARDNER, C. L.; RYMAN, K. D. Yellow fever: a reemerging threat. Clinics in Laboratory Medicine, v. 30, n. 1, p. 237-260. 2010. DOI:10.1016/j.cll.2010.01.001

GUAN, Y. et al. Isolation and characterization of viruses related to the SARS coronavirus from animals in southern China. Science, v. 302, p. 276-278, 2003.

HAMRE, D.; PROCKNOW, J.J. A new virus isolated from the human respiratory tract. Proceedings of the Society for Experimental Biology and Medicine, v.121, p.190-193, 1966.

ICTV - International Committee on Taxonomy of Viruses. Virus Taxonomy: 2019 Release. Berlin, 2020. Disponível em: <talk.ictvonline.org>. Acesso em 20 jun. 2020.

IDEIA Big Data. Ciência, Fake News \& Covid-19. São Paulo, 2020. Disponível em: <https://ideiabigdata.com/ciencia-fake-news-covid19/>. Acesso em 22 jun. 2020.

LAM, T. T. et al. Identifying SARS-CoV-2-related coronaviruses in Malayan pangolins. Nature, 2020. Disponível em: <https://doi.org/10.1038/s41586-0202169-0> Acesso em 21 jun. 2020.

LAU, S.K. et al. Severe acute respiratory syndrome coronavirus-like virus in Chinese horseshoe bats. Proceedings of the National Academy of Sciences of the United States of America, v. 102, p. 14040-14045, 2005.

LE QUERE, C., et al. Temporary reduction in daily global CO2 emissions during the COVID-19 forced confinement. Nature Climate Change, online, 2020. DOI: 10.1038/s41558-020-0797-x

$\mathrm{LI}, \mathrm{W}$. et al. Bats are natural reservoirs of SARS-like coronaviruses. Science, v. 310, p. 676-679, 2005.

LIM, Y.X.; NG, Y.L.; TAM, J.P.; LIU, D.X. Human Coronaviruses: a review of virus-host interactions. Diseases, v. 4, n. 3, online, 2016. DOI: 10.3390/diseases4030026.

LU, R. et al. Genomic characterization and epidemiology of 2019 novel coronavirus: implications for virus origins and receptor binding. Lancet, v. 395, p. 565-574, 2020. DOI: 10.1016/S0140-6736(20)30251-8

MEMISH Z.A. et al. Middle East respiratory syndrome coronavirus in bats, Saudi Arabia. Emerging Infectious Diseases, v. 19, p. 1819-1823, 2013. DOI: 10.3201/eid1911.131172. 
MEMISH, Z. A. et al. Human infection with MERS coronavirus after exposure to infected camels, Saudi Arabia, 2013. Emerging Infectious Diseases, v. 20, p. 1012-1015, 2014. DOI: 10.3201/eid2006.140402

MEYER, B. et al. Antibodies against MERS coronavirus in dromedary camels, United Arab Emirates, 2003 and 2013. Emerging Infectious Diseases, v. 20, p. 552-559, 2014. DOI: 10.3201/eid2004.131746

MORATELLI, R; CALISHER C. H. Bats as reservoirs: Bats and zoonotic viruses: can we confidently link bats with emerging deadly viruses? Memórias do Instituto Oswaldo Cruz, v. 110, n. 1, p. 1-22, 2015.

MOSS, W. J. Measles. Lancet, v. 390, n. 10111, p. 2490-2502, 2017. DOI: 10.1016/S0140-6736(17)31463-0

NASA - National Aeronautics and Space Administration. Airborne Nitrogen Dioxide Plummets Over China. Washington D.C., 2020. Disponível em: $<$ https://earthobservatory.nasa.gov/images/146362/airborne-nitrogen-dioxideplummets-over-china>. Acesso em 21 jun. 2020.

NEWBURGER, E.; JEFFERY, A. As coronavirus restrictions empty streets around the world, wildlife roam further into cities. CNBC Environment, Londres, $\quad 10 \quad$ abr. $2020 . \quad$ Disponível em: $<$ https://www.cnbc.com/2020/04/10/coronavirus-empty-streets-around-theworld-are-attracting-wildlife.html>. Acesso em 22 jun. 2020.

NEWBURGER, E.; JEFFERY, A. Photos show impact of temporary air pollution drops across the world from coronavirus lockdown. CNBC Environment, Londres, 232 abr. 2020.2 Disponível em: $<$ https://www.cnbc.com/2020/04/23/coronavirus-photos-show-effect-of-airpollution-drops-from-global-lockdown.html>. Acesso em 22 jun. 2020.

REGAN, H. Principais cidades do mundo têm redução de até $60 \%$ na poluição do ar. CNN Brasil, São Paulo, 22 abr. 2020. Disponível em: $<$ https://www.cnnbrasil.com.br/internacional/2020/04/22/principais-cidades-domundo-tem-reducao-de-ate-60-na-poluicao-do-ar>. Acesso em 22 jun. 2020.

SHARP, P. M.; HAHN, B. H. Origins of HIV and the AIDS pandemic. Cold Spring Harbor Perspectives in Medicine, v. 1, n. 1, p. a006841, 2011. DOI:10.1101/cshperspect.a006841

SIMS, L.D. et al. Origin and evolution of highly pathogenic H5N1 avian influenza in Asia. Veterinary Record, v. 157, n. 6, p. 159-164, 2005. DOI:10.1136/vr.157.6.159

SMITH, G. et al. Origins and evolutionary genomics of the 2009 swine-origin H1N1 influenza A epidemic. Nature, v. 459, p. 1122-1125, 2009. DOI: 10.1038/nature08182

TIE-GANG, L. et al. Outdoor Air Pollution and Arterial Hypertension In: ARTIS, A. S. (Ed) Blood Pressure - From Bench to Bed. Londres: Intech Open, p. 1941. 2018. 
VAN BOHEEMEN, S. et al. Genomic characterization of a newly discovered coronavirus associated with acute respiratory distress syndrome in humans. MBio, v. 3, n. 6, e00473-12, 2012. DOI:10.1128/mBio.00473-12.

WHO - World Health Organization. WHO timeline - COVID-19. Genebra, 2020a. Disponível em: <https://www.who.int/news-room/detail/27-04-2020-whotimeline---covid-19>. Acesso em 20 jun. 2020.

WHO - World Health Organization. Coronavirus disease (COVID-2019) situation reports. Genebra, 2020c. Disponível em: $<$ https://www.who.int/emergencies/diseases/novel-coronavirus-2019/situationreports/>. Acesso em 20 jun. 2020.

WHO - World Health Organization. Middle East respiratory syndrome coronavirus (MERS-CoV). Genebra, 2020d. Disponível em: $<$ https://www.who.int/emergencies/mers-cov/en/>. Acesso em 21 jun. 2020.

WHO - World Health Organization. Nitrogen dioxide. In: WHO Regional Publications, European Series, No. 91 - Air quality guidelines for Europe. Copenhagen, Denmark: WHO Regional Office for Europe, 2000e.

WHO - World Health Organization. WHO Director-General's statement on IHR Emergency Committee on Novel Coronavirus (2019-nCoV). Genebra, 2020b. Disponível em: <https://www.who.int/dg/speeches/detail/who-directorgeneral-s-statement-on-ihr-emergency-committee-on-novel-coronavirus-(2019$\underline{\text { ncov) })}$. Acesso em 20 jun. 2020.

WOO, P.C. et al. Coronavirus genomics and bioinformatics analysis. Viruses, v. 2, n. 8, p. 1804-1820, 2010.

$\mathrm{XIAO}, \mathrm{K}$. et al. Isolation of SARS-CoV-2-related coronavirus from Malayan pangolins. Nature, 2020. DOI: 10.1038/s41586-020-2313-x>. Acesso em 21 jun. 2020.

ZHU, N. et al. A Novel Coronavirus from Patients with Pneumonia in China, 2019. The New England Journal of Medicine, v. 382, p. 727-733, 2000. DOI: 10.1056/NEJMoa2001017. 